\title{
On-line State Estimator for Three Phase Distribution Networks Displayed on Geographic Information System
}

\author{
Indri Suryawati ${ }^{1}$, Ontoseno Penangsang ${ }^{1}$, Adi Suprijanto ${ }^{1}$, Dimas Fajar U. P. ${ }^{1}$, and Mat Syai' ${ }^{2}{ }^{2}$
}

\begin{abstract}
On line monitoring in distribution system suppose to keep the operation safe and reliable. It is connected measuring sensor that placed in nodes. To minimize great cost of sensors placement, state estimator is needed. This paper proposes online state estimator using neural network. Neural network distribution state estimation solves voltage estimation by using learning approach from power flow patterns. K-matrix distribution power flow is used as analysis method. Detailed information and position of network utility is displayed by Geographic Information System (GIS), control can easily do. NNDSE was design and test for single and three phase network. The results show that NNDSE reduce sensor almost 50\%.
\end{abstract}

Keywords—non-linier hydrodynamic, sloshing, impact, motion.

\section{INTRODUCTION}

$\mathrm{M}$ onitoring and controlling the electrical distribution system for real time is very important to improve its operating performance. To build this monitoring systems, huge number of sensor are needed to monitor all part in the systems. To reduce the investment cost, the number of installed sensor need to be reduced. State estimation approach can be used to estimate the voltage of buses which do not have sensors.

The concept of state estimator was first discovered by Fred Schweppe on the transmission system. The basic idea of the concept is to combine the advantages of measurements using an equations system as to find the conditions that may occur on the network, resulting the minimization of the error of sensor and the delay of sensor readings. Vector estimation in transmission systems consists of voltage magnitude and phase angle [1-3]. State estimation is used in the single phase distribution systems [4-6].

Distribution networks have characteristics such as the radial network topology, the high value of $\mathrm{R} / \mathrm{X}$. There is a lateral system (two-phase and single-phase), and an unbalanced load system. Newton Raphson power flow and fast decouple which is used to analyze the transmission system can't be applied to the distribution system, these methods are built on the assumption of balanced three-phase system.

Several methods have been developed to analyze the distribution system like FB, loopframe, FFRPF, directZBR, these methods have accurate analysis but can't accommodate PV bus [13-18]. The integration of renewable energy sources into the distribution system requires an active distribution power flow to analyze a system performance. The three-phase power flow

${ }^{1}$ Indri Suryawati, Ontoseno Penangsang, Adi Suprijanto, and Dimas Fajar U. P. are with Departement of Electrical Engineering, Faculty of Industry Engineering, Institut Teknologi Sepuluh November, Surabaya, 60111, Indonesia. e-mail: indrisuryawati@gmail.com.

${ }^{2}$ Mat Syai'in is with Department of Marine Electrical Engineering, Surabaya Shipbuilding State Polytechnic Surabaya, 60111, Indonesia. sequence component based method (SPF-NR) easily accommodate PV bus problems. But SPF-NR cannot accommodate lateral system (two-phase network and single phase). K-matrix distribution power flow is a combination of network topology based methods [7] and direct-ZBR method $[8,12]$. K-matrix distribution power flow algorithm is simpler thus more accommodating the changes of the network structure instead of the previous method.

This paper proposes neural network distribution state estimation for online monitoring integrated by geographic information system (GIS). State estimation is solved using learning approach from K-matrix-PSO load flow patterns. Neural Network (NN) is an intelligent computing algorithm that inspired the workings of nerve cells. All incoming input signal is multiplied by the weighting for each input, then summed and added to the bias. The sum of the incoming activation function of the neuron produces output. $\mathrm{NN}$ will bet rained power flow results of K-matrix, as many as 50 load patterns. The goal is not only improve the accuracy but real time measuring. The advantage of GIS for online monitoring; it has two dimension visualization, detailed information of location and flexibility analysis.

\section{METHOD}

The proposed method consists of two stages. The first stage is building Three Phase Radial Distribution Power Flow using K-matrix. The second stage is designing Neural Network Distribution State estimation.

\section{A. K-Matrik Power Flow}

For ease of illustration, the simple three phase radial distribution system is shown in Fig.1. There are five bus and bus no 3 as PV bus. but for this step PV bus is ignored. In other hand the network is passive. The system can be easily analyzed using the $\mathrm{K}$ - matrix power flow method.

$\mathrm{K}$ - matrix is a square matrix with size nbranch $\mathrm{x}$ (nbus - 1). nbranch is the number of branches and nbus is the number of bus. The principle of K-matrix, are looking for the route from bus to reference (bus 1). K-matrix would be worth-C if the branch is located on the opposite lane with reference, $\mathrm{C}$ is a diagonal matrix $(3 \times 3)$ with diagonal elements are 1 in accordance with the number 
of phase. K-matrix formed Figure 1 is expressed in equation (1) as follows:

K-matrix power flow algorithm:

1. Input load and network data

2. Build K-matrix

3. Build BCBV matrix, BCBV is negative transpose $\mathrm{K}$ matrix multiply with full branch matrix [].

4. Build DLF matrix, DLF is BCBV multiply with - (Kmatrix)

Then inflows of at each bus was calculated by equation (2).

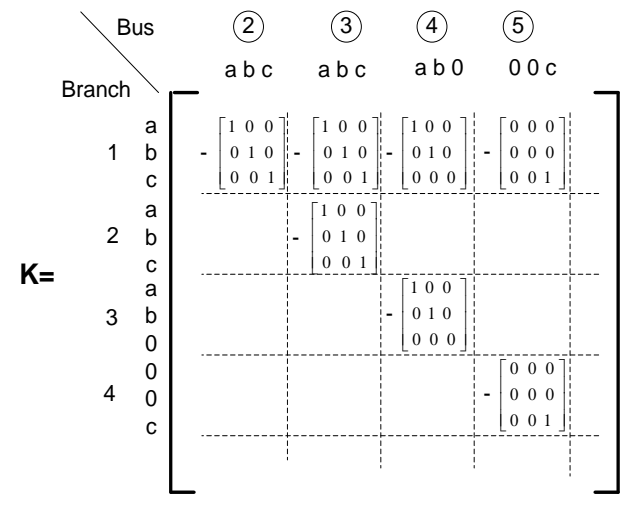

$\mathrm{I}_{\text {bus(i) }}^{(\mathrm{k})}=\left(\frac{\mathrm{P}_{(\mathrm{i})}^{\mathrm{sh}}+\mathrm{jQ}_{(\mathrm{i})}^{\mathrm{sh}}}{\mathrm{V}_{\text {bus }(\mathrm{i})}^{(\mathrm{k})}}\right)$

Equation (3) is updated every iteration. Along with the update iteration, it is the result of multiplying the voltage difference between DLF and $\mathrm{I}_{\mathrm{bus}}^{\mathrm{k}}$

$\Delta \mathrm{V}^{\mathrm{k}}=$ DLFx I $\mathrm{I}_{\text {bus }}^{\mathrm{k}}$

$\mathrm{V}^{\mathrm{k}+1}=\mathrm{V}_{\text {bus_noload }}-\Delta \mathrm{V}^{\mathrm{k}}$

Vbus_noload is the voltage at each bus in the initial conditions, it is set equal to the reference voltage.

Check if $\Delta V_{\mathrm{Bus}}^{(\mathrm{k}+1)}$ are less than a preset tolerance then iteration stop.If it more than a preset tolerance back to point 5 .

\section{B. Neural Network Distribution State Estimator}

Neural Network Distribution State Estimator (NNDSE) is designed and tested for real distribution system. It used one of feeder in Surabaya Indonesia. There are ten bus, six bus is load bus and four bus is no load bus. Sensor was placed on two or more bus. K-matrix power flow patterns divided training and testing, $70 \%$ data as training and $30 \%$ data as testing. In all data use 50 power low patterns. One hidden layer ten node Neural Network back propagation was design.

Artificial neurons are a processing element that functions like neurons in a neural network structure. A number of the input signal is multiplied by each corresponding weights. Then do the sum of all activation function to get the output signal. Suppose there is an input signal and the weights, the output function of the neuron is according the following equation.

$\mathrm{F}_{(\mathrm{x} . \mathrm{w})}=\mathrm{f}\left(\mathrm{w}_{1} \mathrm{x}_{1}+\cdots+\mathrm{w}_{\mathrm{n}} \mathrm{x}_{\mathrm{n}}\right)$

Set of neurons made into a network that will serve as a computational tool. The amount of weight between each neurons connected to be determined the network trained using a set of sample data.

Complete research step is described in Figure 2, Step 1 until 4 is part of stage A and B. Magnitude and angle voltage from 50 load flow pattern from each stage as input and output training testing neural network (step 5). This network was used distribution state estimation (step 6). Module NDSE will export estimation data to database and integrated with GIS to show detail information of location and utility.

\section{RESULT AND ANALYSIS}

First step result is validation power flow design with commercial software, ETAP. The average different values for all design are 0.001. That's mean that all design of power flow are feasible.

Neural network distribution state estimation was tested for following test cases.

\section{A. Single Phase Distribution Network}

There are ten bus in feeder of Kaliasin (Figure.3). bus no 3, 5, 6, 8 and 10 are load bus. Table.1.

Case 1 voltage estimation for bus no 5 and 8 consider three input sensor from bus no 3, 6 and 10 .

Case 2 voltage estimation for bus no 5, 6 and 10, sensor was placed on bus no 3 and no 8 .

\section{B. Passive Three Phase Distribution Network}

Case number two is state estimation for three phase distribution unbalance network. The data was used is feeder of Kaliasin Surabaya Indonesia. Same with Case A but it consist of three phase unbalance load. Table. 2 Case 1 voltage estimation for bus no 5 and consider three input sensor from bus no 3, 6 and 10. Case 2 voltage estimation for bus no 5, 6 and 10, sensor was placed on bus no 3 and 8. NNDSE are obtained. The proposed method accurately solve. On line monitoring GIS based is shown in Figure 4.

\section{CONCLUSION}

Neural network distribution state estimation (NNDSE) which is a new approach to solve for unbalanced distribution networks. The simulation results show that proposed method can accommodate single phase and unbalance three phase. State estimation using neural network for all case have error under $4 \%$ and reduce sensor almost $50 \%$. NNDSE is integrated with GIS, detailed information and location is displayed that monitoring can easily do.

\section{ACKNOWLEDGEMENT}

The author would like to express thanks to Hardina Mulyasari for helping do simulations using CFD

\section{REFERENCES}

[1] F. C. Schweppe and J. Wildes, "Power system static-state estimation, Part I: Exact model," IEEE Trans. Power App. Syst. vol. PAS-89, pp.120-125, Jan. 1970

[2] F. C. Schweppe and D. B. Rom, "Power system static-state estimation, Part II: Approximate model," IEEE Trans. Power App. Syst., vol.PAS-89, pp. 125-130, Jan. 1970.

[3] F. C. Schweppe, "Power system static-state estimation, Part III Implementation," IEEE Trans. Power App. Syst., vol. PAS-89, pp. 262-280,Jan. 1970.

[4] J. Wan and K. N. Miu, "Weighted least squares methods for load estimationin distribution networks," IEEE Trans. Power Syst., vol. 18, no. 4, pp. 1338-1345, Nov. 2003.

[5] K. Li, "State estimation for power distribution system and measurementimpacts," IEEE Trans. Power Syst., vol. 11, no. 2, pp. 911-916, May 1996.

[6] M. Almeida, D. Silveira, and M. F. de Medeiros, Jr., "Estimating loads in distribution feeders using a state estimator algorithm with 
additionaladjustment of transformers loading factors," in Proc. IEEE Int. Symp.Circuits Syst., Bangkok, Thailand, Mar. 2003, vol. 5, pp. III 328-III321.

[7] J. H. Teng, "A Network-Topology Based Three: Phase Load Flow for Distribution Systems," in Proceedings of National Science Council ROC (A), 2000. vol. 24, no. 4: p. p. pp. 259-264.

[8] T. H. Chen and N.C. Yang, "Three-phase power-flow by direct ZBR method for unbalanced radial distribution systems. Generation," in Transmission \& Distribution. IET, 2009. 3(10): p. 903-910.

[9] M. Syai'in, K.L.L., Nien-Che Yang and Tsai-Hsiang Chen, "A Distribution Power Flow using Particle Swarm Optimization," IEEE PES General Meeting 22 - 26 July 2012, San Diego, CA, USA.

[10] Mat Syai'in, Ontoseno Penangsang, and Adi Suprijanto, "Realtime Unbalanced Load Flow Development using direct-ZBR method and Modified Lambda Iteration for On-line Monitoring and Control," in CIRED Sweden, July 2013.

[11] M.Syai'in, O. Penangsang, and A. Suprijanto, "Voltage Estimation using Direct ZBR + Modified Lambda Iteration for On-line Monitoring," in Electrical Power Distribution System(Indexed By IEEEXplore), Kyoto, 2012

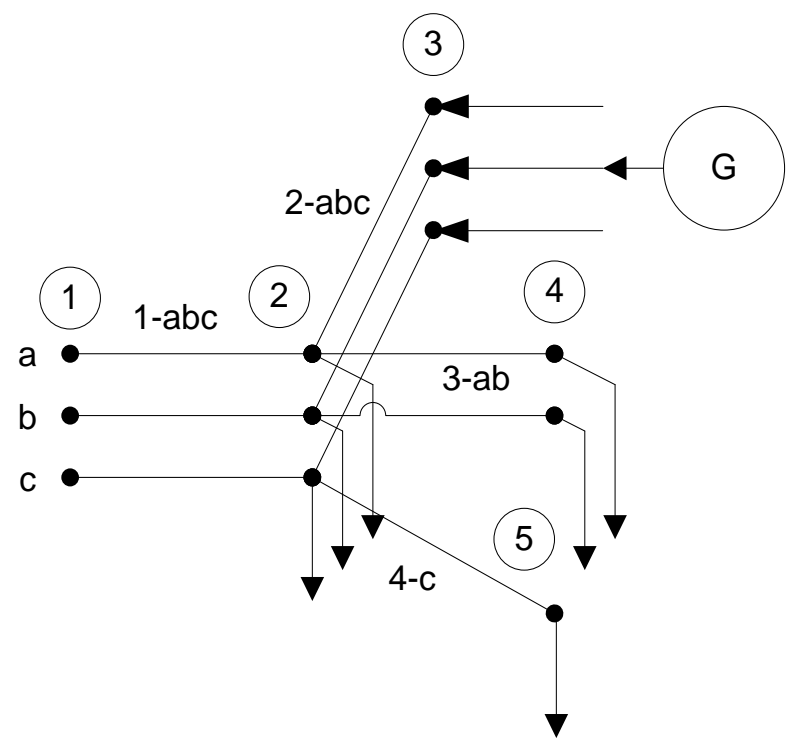

Figure 1. A simple three phase radial distribution system.
[12] T. H. Chen and N. C. Yang, "Three-phase power-flow by direct ZBR method for unbalanced radial distribution systems.Generation," in Transmission \& Distribution, IET, 2009, 3(10): p. 903-910.

[13]P. A. N. Garcia, J.L.R.P., S. Carneiro, V. M. da Costa, and N Martins, "Three-phase power flow calculations using the current injection method," in IEEE Transactions on Power Systems, 2000, $15(2)$.

[14] V. M. da Costa, N.M., and J. L. R. Pereira, "Developments in Newton Raphson power flow formulation based on current injections," in IEEE Transactions on Power System, 1999, 14(4).

[15]W. H. Kersting, "Distribution System Modeling and Analysis," CRC Press, 2002.

[16] J. H. Teng, "A Network-Topology Based Three: Phase Load Flow for Distribution Systems," in Proceedings of National Science Council ROC (A), 2000, vol. 24, no. 4: p. p. pp. 259-264.

[17]K. L. Lo and C. Zhang, "Decomposed three-phase power flow solution using the sequence component frame. Generation," in Transmission and Distribution, IEE Proceedings C, 1993, 140(3) p. 181-188.

[18] Abdel-Akher, M. K. M. Nor, and A. H. A. Rashid, "Improved Three-Phase Power-Flow Methods Using Sequence Components," in Power Systems, IEEE Transactions on, 2005, 20(3): p. 13891397.

[19] M. Z. Kamh and R. Iravani, "Unbalanced Model and Power-Flow Analysis of Microgrids and Active Distribution Systems," in Power Delivery, IEEE Transactions on, 2010, 25(4): p. 28512858.

[20] Kamh, M.Z.a.I., R., "A unified three phase power flow analysis model for electronically coupled distributed energy resources," in IEEE Trans. Power Deliv., 2011, 26(2): p. 899-909.

[21] J. Kenedy, "Particle Swarm Optimization," in IEEE Trans., 1995 26(2): p. 1942-1048.

[22] M. Biserica, Besanger, Y. Caire, R. Chilard, and Deschamps, "Neural Networks to Improve Distribution State Estimation-Vol Var Control Performances," in IEEE Trans. SMART GRID., 2012 3(3): p. 1137-1144.

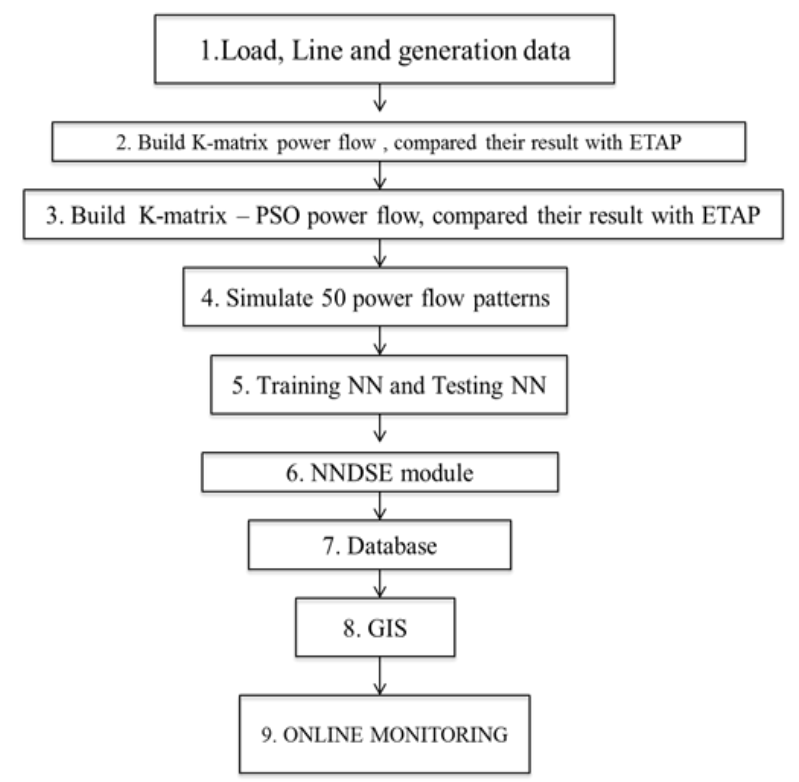

Figure 2. Reseach step 


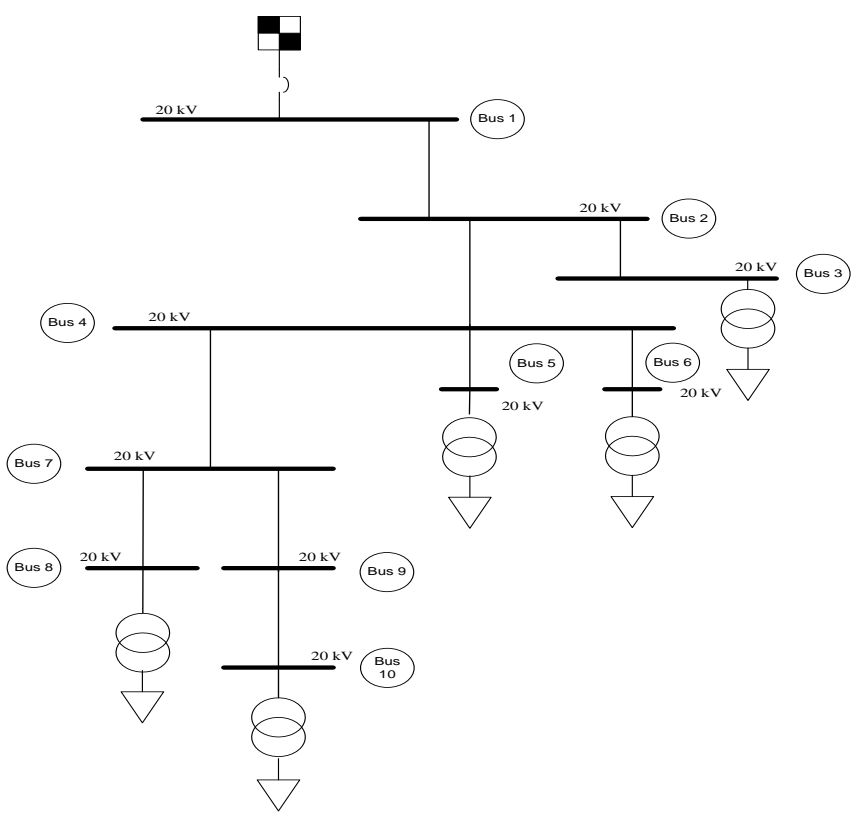

Figure 3. Real distribution system, feeder of kaliasin surabaya indonesia

TABLE 1.

NN STATE ESTIMATION IN SINGLE PHASE DISTRIBUTION NETWORK

\begin{tabular}{|c|c|c|c|c|c|c|c|c|}
\hline & $\begin{array}{l}\text { Case } 1 \\
\text { Voltage (pu) }\end{array}$ & & Angle & & $\begin{array}{l}\text { Case } 2 \\
\text { Voltage (pu) }\end{array}$ & & Angle & \\
\hline \multirow[b]{2}{*}{ Input } & $V_{2}$ & 0.99935 & $\theta_{2}$ & -0.0180 & $V_{2}$ & 0.99935 & $\theta_{2}$ & -0.0180 \\
\hline & & 0.99920 & $\theta_{0}$ & -0.0222 & $V_{a}$ & 0.99916 & $\theta_{0}$ & -0.0233 \\
\hline \multirow{2}{*}{ Target } & $\begin{array}{l}V_{10} \\
V_{s}\end{array}$ & 0.99920 & $\begin{array}{l}\theta_{20} \\
\theta_{5}\end{array}$ & -0.0222 & \multirow{8}{*}{$\begin{array}{l}V_{s} \\
V_{0} \\
V_{10} \\
V_{5} \\
V_{0} \\
V_{20} \\
V_{s} \\
V_{0} \\
V_{10}\end{array}$} & \multirow{8}{*}{$\begin{array}{l}0.99920 \\
0.99920 \\
0.99096 \\
0.99950 \\
0.99970 \\
0.99916 \\
0.03 \% \\
0.05 \% \\
0.83 \%\end{array}$} & \multirow{8}{*}{$\begin{array}{l}\theta_{5} \\
\theta_{5} \\
\theta_{25} \\
\theta_{5} \\
\theta_{5} \\
\theta_{25} \\
\theta_{5} \\
\theta_{5} \\
\theta_{25}\end{array}$} & -0.0222 \\
\hline & & & & & & & & -0.0222 \\
\hline \multirow{6}{*}{ NNDSE } & $V_{a}$ & 0.99916 & $\theta_{a}$ & -0.0233 & & & & -0.0253 \\
\hline & $V_{s}$ & 0.99937 & $\theta_{2}$ & -0.0223 & & & & -0.0227 \\
\hline & & & & & & & & -0.0229 \\
\hline & $V_{a}$ & 0.99927 & $\theta_{a}$ & -0.0238 & & & & -0.0260 \\
\hline & $V_{s}$ & $0.017 \%$ & $\theta_{3}$ & $0.45 \%$ & & & & $2.25 \%$ \\
\hline & $V_{\mathrm{g}}$ & $0.011 \%$ & $\theta$ & $2.14 \%$ & & & & $\begin{array}{l}3 \% \\
2.77 \%\end{array}$ \\
\hline
\end{tabular}

TABLE 2.

NN STATE ESTIMATION IN THREE PHASE DisTRIBUTION NETWORK

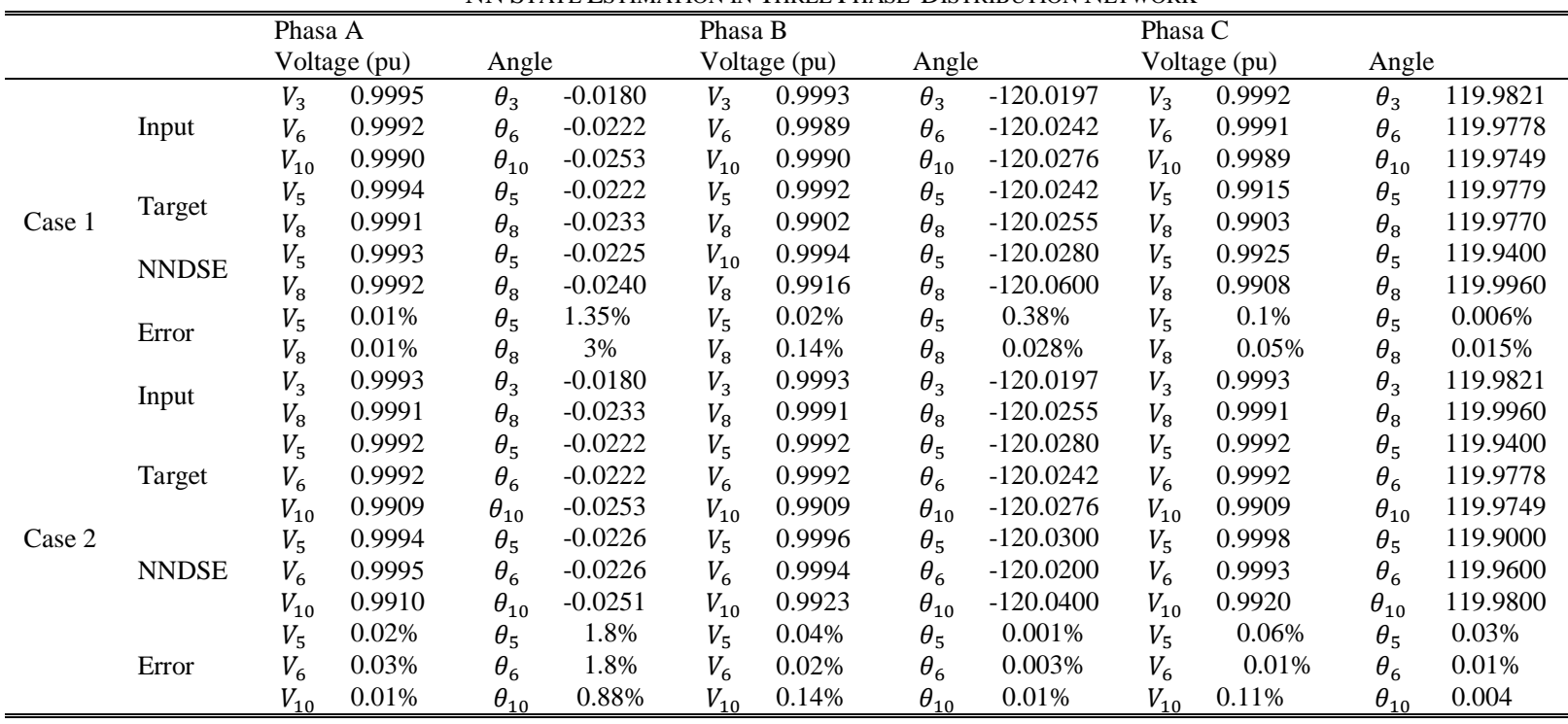

